\title{
Research on the Evolution of Collusion between Government and Civil Construction Enterprises in Environmental Regulation
}

\author{
Cao Yingying ${ }^{1}$ \\ ${ }^{1}$ School of management, Tianjin University of Technology, Tianjin 300384, China
}

\begin{abstract}
Polluting civil construction enterprises usually use the way of "voting with their feet" to exert influence on the efforts of local government's environmental regulation, promote the formation of collusion between government and enterprises, and make the local government relax the supervision on the emission behavior of civil construction enterprises. Based on the Tibert model, this paper uses the evolutionary game method to study the collusion between government and enterprises in the cross regional migration of civil construction enterprises and its prevention. The results show that: when the civil construction enterprises comply with the production, the local government's optimal strategy is non collusion strategy; similarly, when the local government is not willing to collude, the non-collusion choice of civil construction enterprises will get higher benefits than collusion. In addition, the cost of civil construction enterprises transferring between different regions, the loss caused by the collusion between civil construction enterprises and local governments, and the probability of local government violations being found can effectively prevent the collusion between local governments and civil construction enterprises.
\end{abstract}

\section{Introduction}

Polluting enterprises always show their preference for the environmental regulation of local governments. Once the local government strictly supervises the environmental behavior of enterprises and is unwilling to collude with enterprises, the enterprises will flow to other areas with weak environmental regulation. This kind of cross regional flow of enterprises is a typical "Tibert" choice, that is, enterprises can adopt the "foot voting" way such as cross regional flow and transfer investment to achieve the impact on local governments. Furthermore, enterprises are more willing to collude with local governments, and local governments will weaken the supervision of enterprises. For example, in the international, enterprises move from the United States to the countries or regions with weak environmental regulations such as East Asia, but have urgent needs for economic development; in China, the heavy polluting enterprises in the east area migrate to the regions with relatively weak environmental regulation in the West. Behind these phenomena, enterprises can maximize their economic benefits by lobbying local governments to reduce environmental protection, so as to realize mutual benefit between the government and economic elite. From the communique of environmental supervision in China, in the field of environmental management, almost every illegal event has been followed by collusion between the government and enterprises. In recent years, although the construction of government integrity has been on the way, various corruption and illegal behaviors have been paid high attention, but it is still difficult to effectively restrain the collusion between government and enterprises. In fact, the collusion between government and enterprises in the field of environmental management has affected the historical responsibility of the construction of "beautiful China" in China, which seriously damages social welfare, which has become a hot topic in academic circles.

This paper uses evolutionary game theory to study the collusion between government and enterprise and its evolution process when the enterprise has "Tibert" selection characteristics, and brings the behavior decision of participants into the game model, analyzes the evolution trend and evolution law of the population, obtains the evolution law of the strategy of the participants according to the replication dynamic equation, and then studies how to effectively prevent the collusion between local government and enterprise Conspiracy. On the one hand, this study is more in line with the preferences of enterprises in the process of cross regional migration, on the other hand, it is based on the perspective of the overall allocation of public goods to study the collusion between government and enterprises in regional environmental governance.

\section{Model building}

In the game model constructed in this paper, the participants of the game are local government group and enterprise group, and both groups have two strategic choices. Among them, the local government has two strategic choices, one is not willing to collude with the enterprise, the proportion is $x$, the other is willing to collude with the enterprise, the proportion is $1-x$; the

\footnotetext{
*Corresponding author: 13095515027@163.com
} 
enterprise also has two strategic choices, one is not colluding with the local government, the proportion is $y$, the other is actively colluding with the local government, the proportion is $1-y$.

Assuming that the economic income of the enterprise choosing not to collude with the government is $T$, the choice of the enterprise to collude with the government means more economic output, which is set to $T^{\prime}$, where $T^{\prime}>T$. If the enterprise chooses collusion strategy and local government chooses not to collude, the enterprise has the right to vote to move to other areas willing to collude with the enterprise and reduce the intensity of environmental regulation. In the process of the flow, the enterprise has complete information, but it needs to pay the transfer cost $t$ in the process of transfer. If the enterprise and local government collude, it needs to pay the rental fund $K$ and $m$ The possibility of the discovery and the loss found is $E$; when both the enterprise and the local government choose to collude, this indicates that the enterprise forms a conspiracy with the local government in the original area, and the rent-seeking is successful, and the rental fund $K$ is paid to obtain greater economic output, but there is still a certain probability that $\mathrm{M}$ is issued, and once found, it will lose $E$;

Based on the above assumptions, the income matrix of this model is shown in Table 1:

Table 1 Income matrix of enterprises and local governments

\begin{tabular}{c|cc}
\hline Local & \multicolumn{2}{|c}{ Enterprises } \\
\cline { 2 - 3 } governments & No collusion & Collusion \\
\hline \multirow{2}{*}{ Collusion } & $E_{a}=$ & $E_{e}=-W, E_{g}=T^{\prime}-K-$ \\
& $\eta W, E_{e}=T$ & $t-m E$ \\
\multirow{4}{*}{ No collusion } & $E_{b}=\eta W-$ & $E_{d}=\frac{T^{\prime}}{T} \eta W+m(-W)-$ \\
& $n f, E_{f}=T$ & $m F, E_{h}=T^{\prime}-K-m E$ \\
\hline
\end{tabular}

\section{Model analysis}

On the basis of the above model assumptions, the replication dynamic equations of enterprises and local governments are calculated respectively. Suppose that at 0 , the proportion of local government's non-collusion is $x$, then the proportion of collusion is $1-x$; similarly, the proportion of enterprise's non-collusion is $y$, and the proportion of collusion is $1-y$.

The revenue $U_{1}$ and $U_{2}$ of local government departments choosing non-collusion and collusion are:

$$
\begin{aligned}
& U_{1}=y E_{a}+(1-y) E_{e} \\
& U_{2}=y E_{b}+(1-y) E_{d}
\end{aligned}
$$

The income $V_{1}$ and $V_{2}$ of enterprises' choice of noncollusion and collusion are as follows:

$$
\begin{aligned}
& V_{1}=x E_{e}+(1-x) E_{f} \\
& V_{2}=x E_{g}+(1-x) E_{h}
\end{aligned}
$$

According to the relevant evolutionary game theory, the dynamic equation of replication between enterprises and local governments is as follows:

$$
\begin{aligned}
& F(x)=\frac{d x}{d t}=x(1-x)\left[y\left(E_{a}-E_{b}-E_{e}+E_{d}\right)+E_{e}-E_{d}\right] \\
& F(y)=\frac{d y}{d t}=y(1-y)\left[x\left(E_{e}-E_{g}-E_{f}+E_{h}\right)+E_{f}-E_{h}\right]
\end{aligned}
$$

The Jacobian matrix of the equation is:

$$
\begin{gathered}
J=\left[\begin{array}{ll}
J_{1} & J_{2} \\
J_{3} & J_{4}
\end{array}\right] \\
\text { Among } J_{1}=(1-2 x)\left[y\left(E_{a}-E_{b}-E_{e}+E_{d}\right)+E_{e}-E_{d}\right] \\
J_{2}=x(1-x)\left(E_{a}-E_{b}-E_{e}+E_{d}\right) \\
J_{3}=y(1-y)\left(E_{e}-E_{g}-E_{f}+E_{h}\right) \\
J_{4}=(1-2 y)\left[x\left(E_{e}-E_{g}-E_{f}+E_{h}\right)+E_{f}-E_{h}\right]
\end{gathered}
$$

\section{Evolutionary stability analysis of the model}

It can be seen from the previous paper that $0 \leq x \leq 1,0 \leq$ $y \leq 1$, so the analysis interval of the system is $M^{*}=$ $\{(x, y) \mid 0 \leq x, y \leq 1\}$.

According to the relevant constraints in the matrix, $E_{a}>E_{b}$, so there are eight cases shown in Table 2 .

Table 2 Stable point analysis of eight cases

\begin{tabular}{|c|c|c|c|c|}
\hline & $E_{a}-E_{b}$ & $E_{c}-E_{d}$ & $E_{e}-E_{g}$ & $E_{f}-E_{h}$ \\
\hline Case 1 & + & + & + & + \\
\hline Case 2 & + & + & + & - \\
\hline Case 3 & + & + & - & + \\
\hline Case 4 & + & + & - & - \\
\hline Case 5 & + & - & + & + \\
\hline Case 6 & + & - & + & - \\
\hline Case 7 & + & - & - & + \\
\hline Case 8 & + & - & - & - \\
\hline
\end{tabular}

Let $F(x)=0$ and $F(y)=0$, the possible solutions are $(0,0),(0,1),(1,0),(1,1)$ and $\left(x^{*}, y^{*}\right)$, among $x^{*}=$ $\frac{E_{h}-E_{f}}{E_{e}-E_{g}-E_{f}+E_{h}}, \quad y^{*}=\frac{E_{d}-E_{e}}{E_{a}-E_{b}-E_{e}+E_{d}}$. In particular, For $\left(x^{*}, y^{*}\right)$ in plane $M^{*}$, only $\left(E_{h}-E_{f}\right)\left(E_{e}-E_{g}\right)>0$ and $\left(E_{a}-E_{b}\right)\left(E_{d}-E_{e}\right)>0$. Only case 6 exists $\left(x^{*}, y^{*}\right)$ in plane $M^{*}$.

Substituting the above solutions into the matrix $J$, we can get: when the solution is $(0,0), J=$ $\left[\begin{array}{cc}E_{e}-E_{d} & 0 \\ 0 & E_{f}-E_{h}\end{array}\right]$; when the solution is $(1,0), J=$ $\left[\begin{array}{cc}E_{d}-E_{e} & 0 \\ 0 & E_{e}-E_{g}\end{array}\right]$; when the solution is $(0,1), J=$ $\left[\begin{array}{cc}E_{a}-E_{b} & 0 \\ 0 & E_{h}-E_{f}\end{array}\right]$; when the solution is $(1,1), J=$ $\left[\begin{array}{cc}E_{b}-E_{a} & 0 \\ 0 & E_{g}-E_{e}\end{array}\right]$; when the solution is $\left(x^{*}, y^{*}\right), J=$ $\left[\begin{array}{cc}0 & x(1-x)\left(E_{a}-E_{b}-E_{e}+E_{d}\right) \\ y(1-y)\left(E_{e}-E_{g}-E_{f}+E_{h}\right) & 0\end{array}\right]$

According to the determinant and the positive and negative of trace value, the different results are shown in Table 3.

Table 3 Local stability in different cases

\begin{tabular}{|c|c|c|c|}
\hline & Source point & saddle point & Stable point \\
\hline Case 1 & $(0,0)$ & $(0,1),(1,0)$ & $(1,1)$ \\
\hline Case 2 & $(0,1)$ & $(0,0),(1,0)$ & $(1,1)$ \\
\hline Case 3 & $(0,0)$ & $(0,1),(1,1)$ & $(1,0)$ \\
\hline Case 4 & $(0,1)$ & $(0,0),(1,1)$ & $(1,0)$ \\
\hline Case 5 & $(1,0)$ & $(0,0),(1,1)$ & $(1,1)$ \\
\hline
\end{tabular}




\begin{tabular}{|c|c|c|c|}
\hline Case 6 & $(0,1),(1,0)$ & $\left(x^{*}, y^{*}\right)$ & $\begin{array}{r}(0,0), \\
(1,1)\end{array}$ \\
\hline Case 7 & - & $\begin{array}{r}(1,0),(0,0), \\
(1,1),(0,1)\end{array}$ & - \\
\hline Case 8 & $(0,1)$ & $(1,0),(1,1)$ & $(0,0)$ \\
\hline
\end{tabular}

The phase diagrams of different cases are shown in Figure 1 and Figure 2.
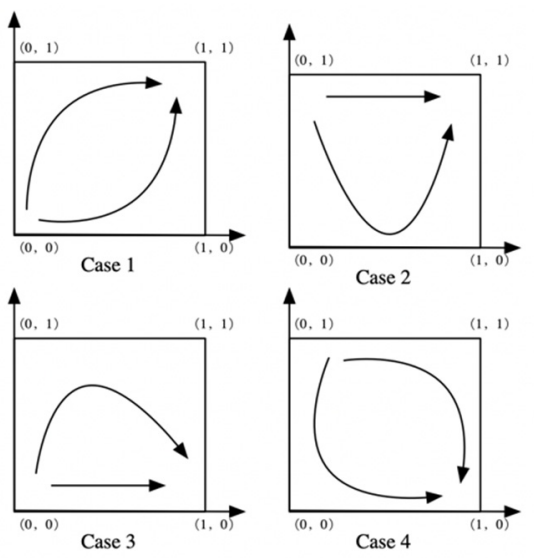

Figure 1 Replication phase diagrams of case 1 to case 4
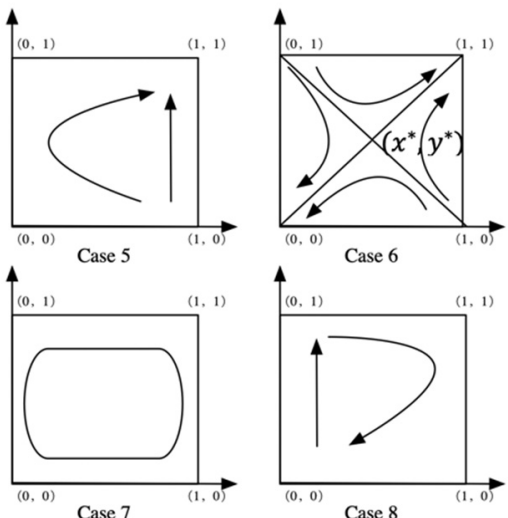

Figure 2 Replication phase diagrams of case 5 to case 8

Among them, the initial states of case 1, case 2 and case 5 are (collusion, collusion), (collusion, non-collusion) and (non-collusion, collusion) respectively. These three cases will eventually evolve to (non-collusion, noncollusion), and all conform to $E_{a}-E_{b}>0$ and $E_{e}-$ $E_{g}>0$. The corresponding practical meaning is that when enterprises tend to choose non-collusion, local governments can obtain higher returns. This shows that when enterprises carry out production activities to comply with the relevant laws and regulations, local governments only choose not to collude in order to avoid the possible punishment. From another point of view, when the local government strictly abides by the relevant laws and regulations, the profit of non-collusion is higher than that of collusion. This shows that the local government chooses not to collude, and the expected profit of noncollusion is much higher than the possible loss of cross regional transfer.

The initial states of case 3 and case 4 are (collusion, collusion) and (collusion, non-collusion) respectively.
After long-term evolution, these two cases will evolve to (non-collusion, collusion), and conform to $E_{a}-E_{b}>0$ and $E_{e}-E_{g}>0$. This shows that when the local government chooses non-collusion, the profit of enterprises choosing collusion is higher than that of noncollusion.

The initial state of case 8 is that the system evolves from (collusion, non-collusion) to (collusion, collusion), and the condition of $E_{a}-E_{b}<0$ and $E_{e}-E_{d}<0$ and $E_{e}-E_{g}<0$ and $E_{f}-E_{h}<0$. The real meaning is that no matter what action choice the enterprise and the local government make, the choice after the long-term evolution of the enterprise is collusion, and the choice after the long-term evolution of the local government is collusion, which is invalid at this time.

Case 7 shows that local governments and enterprises always maintain periodicity in the process of evolution, which is not suitable for the analysis of this paper.

In case 6 , there are five equilibrium points, where $(0,1)$ and $(1,0)$ are the source points, $(0,0)$ and $(1,1)$ are the stable points, $\left(x^{*}, y^{*}\right)$ are the saddle points, where $x^{*}=\frac{E_{h}-E_{f}}{E_{e}-E_{g}-E_{f}+E_{h}}, \quad y^{*}=\frac{E_{d}-E_{e}}{E_{a}-E_{b}-E_{e}+E_{d}}$, the connection lines of two unbalanced points $(0,1)$ and $(1,0)$ at the saddle points $\left(x^{*}, y^{*}\right)$ are the critical lines for the convergence of the system to two different modes. The change of different parameters will make the saddle point position change. By studying the regulation of the change of parameters on the behavior of game players, the system can evolve to the ideal mode.

\section{Analysis and control of model parameters}

The evolution of case 6 is the most complex. In this case, there are two kinds of strategic choices between local government and enterprises, namely (collusion, collusion) and (non-collusion, non-collusion). Although collusion is the best choice, only in the region s surrounded by points $(0,1)$ and $(0,1)$ and $(1,1)$ saddle points $\left(x^{*}, y^{*}\right)$, the system achieves the best. The parameters affecting the area of area s are analyzed and controlled. In this case,

$$
\begin{gathered}
S=1-\frac{1}{2}\left(x^{*}+y^{*}\right) \\
S=1-\frac{1}{2}\left(\frac{E_{h}-E_{f}}{E_{e}-E_{g}-E_{f}+E_{h}}+\frac{E_{d}-E_{e}}{E_{a}-E_{b}-E_{e}+E_{d}}\right) \\
\text { Among } x^{*}=\frac{E_{h}-E_{f}}{E_{e}-E_{g}-E_{f}+E_{h}}=\frac{T^{\prime}-K-m E-T}{t} \\
y^{*}=\frac{E_{d}-E_{e}}{E_{a}-E_{b}-E_{e}+E_{d}} \\
=\frac{(1-m) W \times\left(\frac{T^{\prime}}{T} \eta+1\right)-m F}{n f+(1-m) W \times\left(\frac{T^{\prime}}{T} \eta+1\right)-m F}
\end{gathered}
$$

Table 4 The influence of each parameter change on the optimal state of the system

\begin{tabular}{|c|c|c|}
\hline parameter change & Saddle point change & Area $\mathrm{S}$ \\
\hline$t \uparrow$ & $x \downarrow$ & $S \uparrow$ \\
\hline$n \uparrow$ & $y^{*} \downarrow$ & $S \uparrow$ \\
\hline
\end{tabular}




\begin{tabular}{|c|c|c|}
\hline$E \uparrow$ & $x^{*} \downarrow$ & $S \uparrow$ \\
\hline$F \uparrow$ & $y^{*} \downarrow$ & $S \uparrow$ \\
\hline
\end{tabular}

According to the above, the following conclusions can be drawn:

Proposition 1: The optimal area of the system evolution is positively related to the trans regional transfer cost of polluting enterprises.

Proposition 2: The more easily the violations of local government are found, the larger the area of the system evolving to the optimal.

Proposition 3: The larger the loss of collusion is found, the larger the optimal area of the system is.

Proposition 4: The greater the loss of local government after collusion is found, the more likely the system will evolve to the optimal area.

\section{Conclusion}

For the local government, when the enterprises choose not to collude, the local government will get higher income; for the enterprises, similar to the local government, when the local government does not collude, the enterprise will get higher income. In other words, when either party of the game does not collude, the enterprise environmental behavior will evolve to the direction of compliance.

The higher the cost of trans regional transfer, the more likely the players are to choose non-collusion. Enterprises take profit as the goal, and "cooperation" between enterprises and local governments is only to seek lower compliance cost, which can't be met. Enterprises will choose to transfer across regions and cooperate with other parties to continue to seek lower compliance cost. In the behavior of enterprises choosing transfer, the cost of trans regional transfer is an important factor to decide whether the enterprises collude or not.

The higher the possibility of local government violations being found, the more likely both sides of the game are to choose non-collusion. If we can't carry out the effective supervision on the work of local government, it will make the local government have higher moral hazard. Effective social supervision can supervise the local government, restrict its behavior, avoid the occurrence of illegal behavior, and cut off the interest chain between enterprises and local government.

The greater the loss caused by the collusion between government and enterprise, the more likely both sides of the game choose not to collude. If the local government is expected to face lower losses, the higher the possibility of moral hazard of local government, the more enterprises will choose to collude with the local government. For enterprises, the possible losses mainly include related penalties and reputation loss.

\section{Reference}

1. J.E. Stiglitz. Incentives, risk, and information: notes toward a theory of hierarchy [J]. Bell Journal of Economics, 1975, 6(2): 552-579.

2. L.M. Bartels, H.E. Brady. Economic behavior in political context [J]. American Economic Review, 2003, 93(93): 156-161.

3. H. Li, L. Meng, J. Zhang. Why do entrepreneurs enter politics? Evidence from China [J]. Economic Inquiry, 2006,44(3): 559-578.

4. A. Dreher, M. Gassebner. Greasing the wheels of entrepreneurship? Impact of regulations and corruption on firmentry[J]. Social Science Electronic Publishing, 2007, 155(4):413-432.

5. A. Burlando, A. Motta. Collusion and the organization of the firm [J]. New Phytologist, 2015, 166(1): 9-231.

6. Q. Wei, H. Liu. Research of the game and countermeasure about collusion between executives of state-owned enterprises and government officials [J]. Journal of Service Science \& Management, 2015, 8(4): 536-544. 